\title{
Systematic Review and Meta-analysis on Oral azoles for the Treatment of Pityriasis Versicolor
}

\author{
Rowena Natividad S. Flores-Genuino, ${ }^{1,2,3}$ Belen L. Dofitas, ${ }^{4}$ Leonila F. Dans ${ }^{5}$ and Ma. Lourdes E. Amarillo ${ }^{6}$ \\ ${ }^{1}$ Department of Anatomy, College of Medicine, University of the Philippines Manila \\ ${ }^{2}$ Manila Doctors Hospital \\ ${ }^{3}$ Makati Medical Center \\ ${ }^{4}$ Section of Dermatology, College of Medicine and Philippine General Hospital, University of the Philippines Manila \\ ${ }^{5}$ Department of Pediatrics, College of Medicine and Philippine General Hospital, University of the Philippines Manila \\ ${ }^{6}$ Department of Clinical Epidemiology, College of Medicine, University of the Philippines Manila
}

\begin{abstract}
Background. Oral azole drugs are a second-line option for the treatment of pityriasis versicolor but evidence on their efficacy and safety is unclear.

Objectives. To determine the efficacy and safety of oral azoles in the treatment of patients with pityriasis versicolor. Methods: We searched MEDLINE, CENTRAL, EMBASE, LILACS, and HERDIN, from inception to the period between January to February 2014. We did not restrict the search by language or publication status.

We included randomized controlled trials (RCTs) that compared the efficacy of oral azoles with placebo or no treatment, with topical agents, other oral azoles or dosing regimens in the treatment of pityriasis versicolor, and that measured any of the pre-specified outcomes (mycologic cure, clinical cure, recurrence, duration to cure, timeto-cure, and quality of life). For adverse effects, we also included non-randomized studies (NRS). We used Cochrane methods to select studies, extract data, assess risk of bias, pool studies, and calculate for treatment effects.
\end{abstract}

Results. We included 38 RCTs ( $n=2894)$ and 56 NRS ( $n=3452)$. Overall, there were few pooled studies and evidence was low to moderate quality.

Oral azoles were more effective than placebo (mycologic cure, RR 11.34, 95\% Cl 4.90, 26.28; 3 RCTs, $n=131 ; l^{2}=0 \%$; low quality of evidence) and as effective as topical agents (mycologic cure, RR 1.02, 95\% Cl 0.86, 1.21; 4 RCTs, $\mathrm{n}=232 ; \mathrm{I}^{2}=60 \%$; moderate quality of evidence).

There were few adverse effects and were mostly minor and transient.

Conclusions. Oral azoles may be more effective than placebo, and are probably as effective as topical agents in the treatment of PV. Triazoles are probably as effective as ketoconazole. Adverse effects were few, mostly minor, and transient.

Key Words: oral azole, ketoconazole, itraconazole, fluconazole, tinea versicolor, pityriasis versicolor, systematic review, meta-analysis

Presented at the University of the Philippines Manila College of Medicine Faculty Research Forum on September 28, 2017, UPCM Calderon Hall Building, Ermita, Manila Philippines.

Corresponding author: Rowena Natividad Flores-Genuino, MD Department of Anatomy

College of Medicine

University of the Philippines Manila

547 Pedro Gil Street, Ermita, Manila 1000, Philippines

Telephone: +6325264194

Email: rfgenuino@post.upm.edu.ph

\section{INTRODUCTION}

Pityriasis versicolor $(\mathrm{PV})$ is a common, benign, but highly recurrent superficial skin infection caused by Malassezia spp, a normal commensal yeast. Persistent skin discoloration may lead to emotional, social, and psychological distress. ${ }^{1}$ Firstline topical agents are effective but may be inadequately applied or inconvenient to use for extensive areas, and may result in treatment failure due to poor patient compliance.,3 
Oral azoles are used off-label in extensive, recurrent, or recalcitrant PV. Mycologic cure rates of $80 \%$ and above have been shown over a range of different dosing regimens, except single dose regimens. ${ }^{4}$ Oral ketoconazole was banned or restricted since 2013 in several countries, including the European Union, ${ }^{5}$ US, ${ }^{6}$ and the Philippines, ${ }^{7}$ due to serious hepatotoxicity, drug interactions, and adrenal suppression.

A previous systematic review that searched up to 2008 concluded that oral azoles are effective versus placebo in treating PV, but its efficacy compared to topical agents, other oral azoles, and dosing regimens is still unknown. ${ }^{2}$ However, this previous review pooled non-randomized and randomized trials and used risk difference, a less stable effect estimate.

This review aimed to determine the efficacy and safety of oral azoles in the treatment of PV.

\section{METHODS}

This study was conducted according to the Cochrane Handbook for Systematic Reviews of Interventions and the statement by the Preferred Reporting Items for Systematic Reviews and Meta-Analyses Group (PRISMA). The review protocol is available upon request from the corresponding author.

\section{Search Methods}

We searched the following databases from inception to the period between January to February 2014: CENTRAL in the Cochrane library (2014 Issue 10), MEDLINE (from 1946), EMBASE (from 1974), LILACS (from 1982), HERDIN (from 1971). We separately searched MEDLINE for adverse effects. The search strategies used for MEDLINE are outlined in Table S1. We also searched six trial registries, reference lists, and selected dermatologic journals and conference proceedings. We contacted researchers, organizations, and local pharmaceutical companies.

\section{Selection criteria}

We included RCTs for efficacy outcomes, and RCTs and non-randomized studies for safety outcomes if they 1) included patients with pityriasis versicolor; 2) compared oral azole (ketoconazole, itraconazole, fluconazole) with no comparator, placebo or no treatment, topical agents, other oral azoles or dosing regimens; 4) measured mycologic cure, clinical cure, recurrence, duration to cure, time-to-cure, quality of life, and adverse effects; and 5) type of studies: We included studies in any language or publication status. We excluded case reports and case series. Two reviewers independently screened titles and abstracts, then assessed full texts of selected studies for final inclusion in the review.

\section{Data extraction and analysis}

Two reviewers extracted data and assessed risk of bias (using the Cochrane Collaboration Risk of Bias tool) using pre-piloted data extraction forms. We resolved discrepancies by discussion or consultation with a third reviewer. Variables pertaining to participants (e.g., age, sex, extent of $\mathrm{PV})$, intervention and comparator (e.g., dosing regimen), outcomes (e.g., assessment method, person measuring outcome), and other information (e.g., funding source) were collected. We attempted to obtain missing or unclear information from study authors through electronic mail communication. We pooled similar studies and performed random effects meta-analyses using RevMan 5.38 (for controlled trials) and StatsDirect ${ }^{9}$ (single-arm trials). For dichotomous outcomes, we calculated for relative risk and 95\% confidence intervals (controlled trials), or absolute risk and $95 \%$ CIs (single-arm trials). For continuous outcomes, we computed for differences in means and standard deviations. Serious adverse effects including those requiring treatment discontinuation were described.

Heterogeneity was assessed using $\mathrm{I}^{2}$, with a value greater than $50 \%$ considered as significant heterogeneity. Subgroup analyses were done to investigate heterogeneity and to determine the impact of extent of PV, climate, and dosing regimen. Funnel plot analysis was planned to detect publication bias but there were few pooled studies. We did sensitivity analyses to test the robustness of our results. We rated the quality of evidence and constructed summary of findings tables using GRADE. ${ }^{10}$

\section{RESULTS}

We retrieved 109 potentially eligible studies, 94 of which fulfilled the inclusion criteria. We excluded two studies each on prophylaxis ${ }^{11,12}$ and pramiconazole, ${ }^{13,14}$ and two case reports. ${ }^{15,16}$ Eleven studies are awaiting translation, ${ }^{17-20}$ further information on adverse effect outcomes, ${ }^{21-24}$ or separate data for $\mathrm{PV}$ patients. ${ }^{25-27}$ We included $38 \mathrm{RCT}$ s for efficacy assessment, and an additional 56 controlled clinical trials (CCTs)/single-arm trials (SATs) for safety assessment (Figure 1).

\section{A. Randomized Controlled Trials (RCTs)}

\section{Description of included studies}

Trials included mostly children and adults (range 8 to 85 years) with PV. Moderate to extensive or recurrent PV was included in only 14 studies, and unspecified in the rest (24). Trials were conducted in both tropical (23) and non-tropical countries (18).

Three types of oral azoles were given as either intervention or comparator, and in widely varied regimens (single dose, daily or pulsed dose). Ketoconazole was most commonly given at $200 \mathrm{mg} /$ day for 7 to 14 days (11 studies); itraconazole, at 100 to $200 \mathrm{mg} /$ day for 5 to 14 days (23); and fluconazole, at $150 \mathrm{mg}$ to $400 \mathrm{mg}$ weekly or bimonthly (11). Oral azoles were compared with placebo, ${ }^{28-33}$ topical agents, ${ }^{34-42}$ other oral azoles, ${ }^{42-47}$ other dosing regimens, ${ }^{43,46-58}$ or various comparators ${ }^{54,59-62}$ (Tables S2 to S6). Compliance 


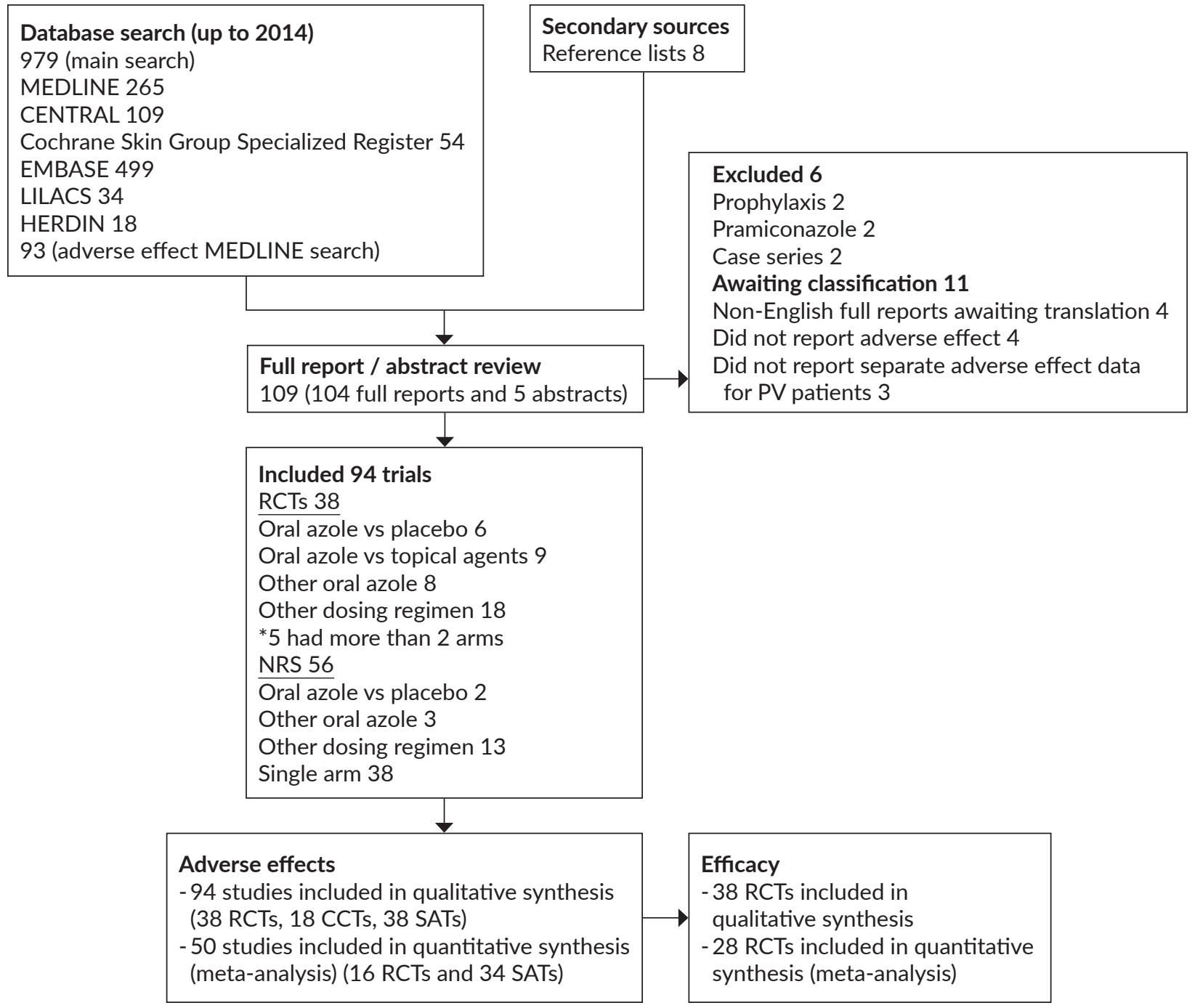

Figure 1. Study flow diagram.

was only reported in two trials, but the method used was unclear.

Mycologic cure (30) was reported more than clinical cure (17) or recurrence (12). Clinical adverse effects (37) were reported more than laboratory test results (25). Passive detection of clinical adverse effects (18) was done more than active surveillance (4). No study reported time-to-cure or quality of life outcomes.

Reports were mostly published in English (33) and during the 1990s (15). Most were small-sized (less than 50 participants) (22) and had pharmaceutical funding/affiliation (15) or undisclosed funding/conflict of interest (20).

\section{Risk of bias in included studies}

Overall, reporting was poor and risk of bias was generally unclear or high risk (Figures S1 and S2). Thirtyfour studies had high risk of bias in at least one domain. The most common high risk domains were blinding of participants and personnel (30) and blinding of outcome assessors (28). Selective reporting bias was high risk in 18 studies. Rrandomization (34) was generally unclear and allocation concealment methods were high risk (6) or poorly described (27).

\section{Effects of Interventions}

Only one comparison (oral azole vs placebo) showed a significant difference. Other comparisons (between oral azole and topical agents, between different oral azoles, between different dosing regimens of same oral azole) did not show any significant differences.

Oral azole vs placebo. We pooled three trials (sample size range 33 to 72) that compared either oral ketoconazole, ${ }^{32}$ itraconazole $^{30}$ and fluconazole ${ }^{28}$ with placebo (S.Table 2). One trial (Savin 1984) ${ }^{32}$ specified extent of PV (moderate to extensive), and gave ketoconazole for four weeks, which was longer than recommended (one week). There was a significant and large treatment benefit favoring oral azoles over placebo for mycologic cure and clinical cure (Figure 2). 


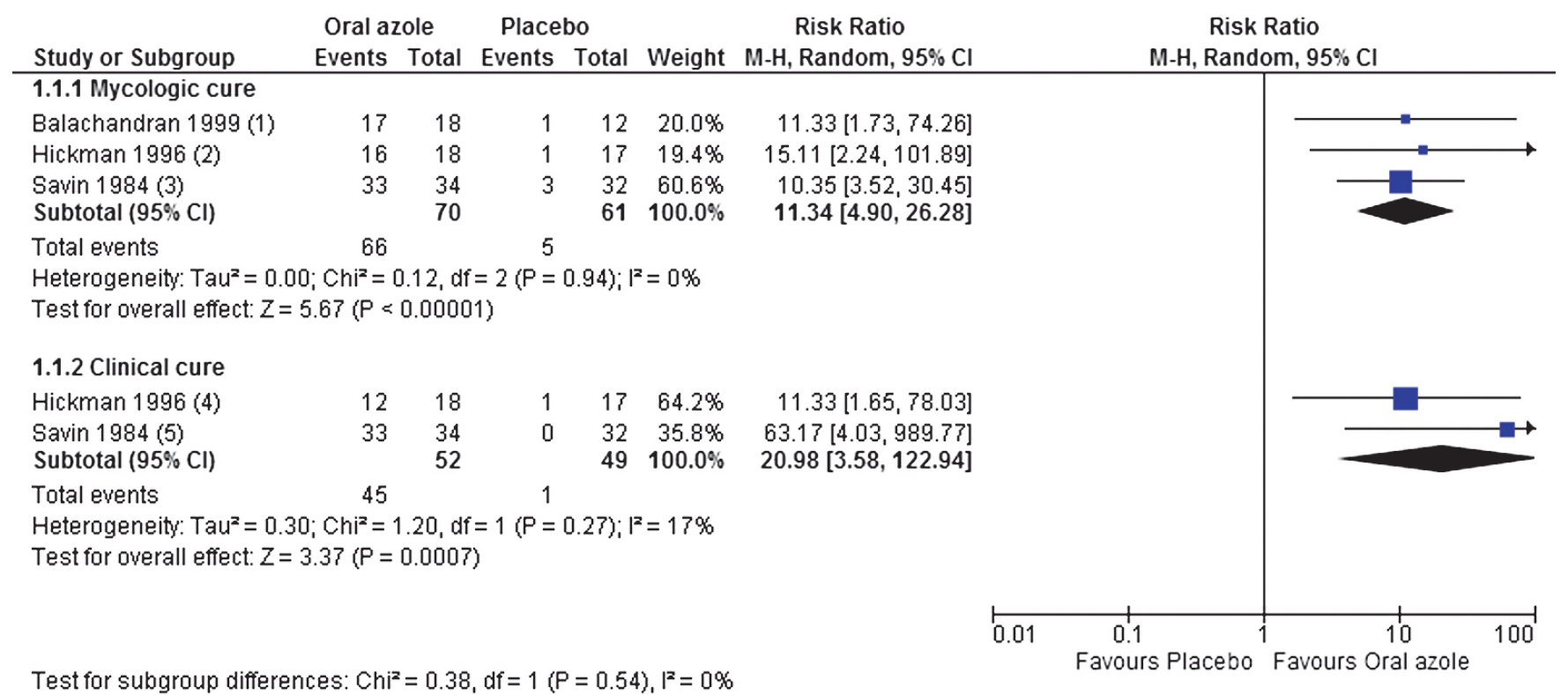

Footnotes
(1) end of $2-4 w k t x$
(2) 4 wks post-tx
(3) end of $4-w k t x$
(4) 4 wks post-tx
(5) end of 4-wktx (same as 8 wks post-tx)

Figure 2. Oral azole versus placebo: mycologic cure and clinical cure.

Table 1. Summary of treatment effects showing equivalent efficacy between groups in four meta-analyses

\begin{tabular}{|c|c|c|c|c|c|c|}
\hline $\begin{array}{l}\text { Outcomes } \\
\text { (weeks post-treatment) }\end{array}$ & $\begin{array}{l}\text { No. of participants } \\
\text { (No. of trials) }\end{array}$ & $\begin{array}{l}\text { Experimental No. } \\
\text { (\%) }\end{array}$ & $\begin{array}{l}\text { Control No. } \\
\text { (\%) }\end{array}$ & $\begin{array}{l}\text { Relative risk } \\
(95 \% \mathrm{Cl})\end{array}$ & Test for heterogeneity & $\begin{array}{l}l^{2} \\
(\%)\end{array}$ \\
\hline \multicolumn{7}{|c|}{ Oral azole vs topical agent } \\
\hline $\mathrm{MC}(0$ to 3$)$ & $232(4)$ & $99 / 116(85.3)$ & $99 / 116(85.3)$ & $1.02[0.86,1.21]^{*}$ & $\mathrm{Chi}^{2}=7.55, \mathrm{df}=3(\mathrm{P}=0.06)$ & 60 \\
\hline CC (0 to 4$)$ & 293(5) & $120 / 143(83.9)$ & $132 / 150(88.0)$ & $0.94[0.86,1.03]^{*}$ & $C h i^{2}=3.72, d f=4(P=0.59)$ & 0 \\
\hline Recurrence (various) & $125(3)$ & $3 / 65(5)$ & $9 / 60(15)$ & $0.35[0.11,1.09]^{*}$ & $\mathrm{Chi}^{2}=0.25, \mathrm{df}=2(\mathrm{P}=0.88)$ & 0 \\
\hline Duration to MC (wks.) & $126(3)$ & 3 to 3.8 & 3.35 to 3.36 & $-0.31[-0.61,-0.00]^{*}$ & $\mathrm{Chi}^{2}=0.58, \mathrm{df}=2(\mathrm{P}=0.75)$ & 0 \\
\hline CAE & $96(2)$ & $1 / 34(2 / 9)$ & $5 / 62(80.6)$ & $0.84[0.01,77.21]^{*}$ & $C h i^{2}=4.57, d f=1(P=0.03)$ & 78 \\
\hline \multicolumn{7}{|l|}{ Triazole vs ketoconazole } \\
\hline $\mathrm{MC}(0$ to 6$)$ & $487(4)$ & $227 / 259(87.6)$ & $192 / 228(84.2)$ & $1.04\left[0.94,1.15\left[^{*}\right.\right.$ & $\mathrm{Chi}^{2}=5.92, \mathrm{df}=3(\mathrm{P}=0.12)$ & 49 \\
\hline CC (0 to 4$)$ & 153(1) & $63 / 78(81)$ & $63 / 75(84)$ & $0.96[0.83,1.11]^{*}$ & N/A & N/A \\
\hline MR (various) & $232(2)$ & $9 / 116(7.8)$ & $11 / 116(9.5)$ & $0.75[0.10,5.63]^{*}$ & $\mathrm{Chi}^{2}=4.41, \mathrm{df}=1(\mathrm{P}=0.04)$ & 77 \\
\hline \multicolumn{7}{|c|}{ Low dose/long duration vs standard dose/duration } \\
\hline $\mathrm{MC}(3$ to 7$)$ & $90(2)$ & $43 / 46(93.5)$ & $40 / 44(90.9)$ & $1.03[0.94,1.13]^{*}$ & $\mathrm{Chi}^{2}=0.07, \mathrm{df}=1(\mathrm{P}=0.80)$ & 0 \\
\hline CC (3) & $30(1)$ & $13 / 15$ & $12 / 15$ & $1.08[0.79,1.49]^{*}$ & N/A & N/A \\
\hline \multicolumn{7}{|c|}{ Divided daily dose vs single daily dose } \\
\hline $\mathrm{MC}(4)$ & $54(2)$ & $30 / 30(100)$ & $24 / 24(100)$ & $1.00[0.91,1.10]^{*}$ & $\mathrm{Chi}^{2}=0.00, \mathrm{df}=1(\mathrm{P}=1.00)$ & 0 \\
\hline CC (4) & $28(1)$ & $15 / 15(100)$ & $13 / 13(100)$ & $1.00[0.87,1.14]^{*}$ & N/A & N/A \\
\hline CAE & $60(2)$ & $2 / 30(66.7)$ & $6 / 30(20)$ & $0.60[0.01,37.08]^{*}$ & $\mathrm{Chi}^{2}=4.11, \mathrm{df}=1(\mathrm{P}=0.04)$ & 76 \\
\hline
\end{tabular}

MC Mycologic cure; CC clinical cure; CAE Clinical adverse effects; df degrees of freedom: P p-value; * not statistically significant; NA Not applicable

There was no significant difference between oral azoles and placebo for clinical adverse effects (RR 1.55, 95\% CI 0.32, 7.66; 3 RCTs, $\left.\mathrm{n}=131 ; \mathrm{I}^{2}=0 \%\right)$.

Other comparisons. Four comparisons (oral azole vs topical agent, triazole vs ketoconazole, low dose/long duration vs standard dose/duration, divided daily dose vs single daily dose) (Table 1) showed equivalent efficacy. There were no significant differences between groups for adverse effects.
Three other pooled comparisons (fluconazole vs itraconazole, single dose vs multiple dose, low dose vs standard dose) did not show any significant difference in efficacy and safety (Table 2).

Four other individual studies which compared various dosing regimens (5-day vs 15 -day vs 25 -day ketoconazole, ${ }^{59} 1$-day vs 3 -day vs 5 -day itraconazole; ${ }^{60}$ 1 -week vs 2 -week vs 4 -week fluconazole; ${ }^{4} 50 \mathrm{mg}$ vs $100 \mathrm{mg}$ 
Table 2. Summary of treatment effects for 3 comparisons with no significant difference in efficacy

\begin{tabular}{|c|c|c|c|c|c|c|}
\hline $\begin{array}{l}\text { Outcomes } \\
\text { (weeks post-treatment) }\end{array}$ & $\begin{array}{l}\text { No. of participants } \\
\text { (No. of trials) }\end{array}$ & $\begin{array}{l}\text { Experimental No. } \\
\text { (\%) }\end{array}$ & $\begin{array}{l}\text { Control No. } \\
\text { (\%) }\end{array}$ & $\begin{array}{l}\text { Relative risk } \\
(95 \% \mathrm{Cl})\end{array}$ & Test for heterogeneity & $\begin{array}{l}l^{2} \\
(\%)\end{array}$ \\
\hline \multicolumn{7}{|l|}{ Fluconazole vs itraconazole } \\
\hline $\mathrm{MC}$ (3 to 8 ) & $301(3)$ & $128 / 167(76.7)$ & $100 / 134(74.6)$ & $1.05[0.79,1.39]^{*}$ & $\mathrm{Chi}^{2}=6.52, \mathrm{df}=2(\mathrm{P}=0.04)$ & 69 \\
\hline CC (3 to 8$)$ & $130(2)$ & $54 / 80(67.5)$ & $29 / 50(58.0)$ & $1.23[0.61,2.47]^{*}$ & $\mathrm{Chi}^{2}=3.76, \mathrm{df}=1(\mathrm{P}=0.05)$ & 73 \\
\hline Mycologic recurrence & $211(2)$ & $17 / 116(14.7)$ & $14 / 95(14.7)$ & $1.35[0.09,19.49]^{*}$ & $\mathrm{Chi}^{2}=5.92, \mathrm{df}=1(\mathrm{P}=0.01)$ & 83 \\
\hline CAE & $40(1)$ & $1 / 20(5.0)$ & $0 / 20(0)$ & $3.00[0.13,69.52]^{*}$ & N/A & N/A \\
\hline \multicolumn{7}{|c|}{ Single dose vs multiple dose } \\
\hline $\mathrm{MC}(0$ to 6$)$ & $411(5)$ & $140 / 210(66.7)$ & $152 / 210(72.4)$ & $0.87[0.75,1.00]^{*}$ & $\mathrm{Chi}^{2}=6.29, \mathrm{df}=4(\mathrm{P}=0.18)$ & 36 \\
\hline CC (0 to 4$)$ & 263(3) & $102 / 130(78.5)$ & 104/133 (78.2) & $0.98[0.79,1.21]^{*}$ & $\mathrm{Chi}^{2}=4.11, \mathrm{df}=2(\mathrm{P}=0.13)$ & 51 \\
\hline MR (3 to 12 mos.) & $161(2)$ & $12 / 75(16)$ & $9 / 86(10.5)$ & $1.60[0.73,3.54]^{*}$ & $\mathrm{Chi}^{2}=0.26, \mathrm{df}=1(\mathrm{P}=0.61)$ & 0 \\
\hline \multicolumn{7}{|l|}{ Low dose vs standard dose } \\
\hline $\mathrm{MC}$ (3 to 4$)$ & $516(4)$ & $213 / 270(78.9)$ & $228 / 246(92.7)$ & $0.89[0.76,1.06]^{*}$ & $\mathrm{Chi}^{2}=11.78, \mathrm{df}=3(\mathrm{P}=0.008)$ & 75 \\
\hline CAE & $119(3)$ & $3 / 63(4.8)$ & $10 / 56(17.9)$ & $0.34[0.11,1.11]^{*}$ & $\mathrm{Chi}^{2}=0.75, \mathrm{df}=2(\mathrm{P}=0.69)$ & 0 \\
\hline
\end{tabular}

MC Mycologic cure; CC clinical cure; CAE Clinical adverse effects; df degrees of freedom: P p-value; ${ }^{*}$ not statistically significant

itraconazole ${ }^{62}$ ) showed no significant difference in efficacy and safety (Table S11).

Subgroup and sensitivity analyses done based on prespecified (i.e., extent of PV, type of climate, method of skin collection, impact of missing data, funding source) and posthoc variables (i.e., type of oral azoles, type of comparator agent, definition of microscopic or clinical cure, varying time points of assessment, unavailability of full text, year of publication) were not conclusive due to few pooled studies and poor reporting of details of studies.

\section{B. Non-randomized Studies (NRS)}

\section{Description of included studies}

The age of participants ranged from 4 months to 92 years, and most studies included both children and adults (21). All studies included both male and female participants. Participants with extensive/recurrent PV were recruited in 19 studies. Studies were conducted in both tropical (32) and non-tropical countries (25).

Three oral azoles, ketoconazole (30), itraconazole (19), and fluconazole (10) were given in widely varied regimens in $18 \mathrm{CCTs}(\mathrm{N}=1643)$. An oral azole was compared with placebo (2 CCTs; $\mathrm{n}=49) ;{ }^{64,65}$ another oral azole $(3 \mathrm{CCT}$; $\mathrm{n}=$ $230),{ }^{66-68}$ or another dosing regimen $(13 \mathrm{CCTs} ; \mathrm{n}=1364)^{69-}$ ${ }^{81}$ (Tables S7 to S9). Thirty-eight single-arm trials (SATs) were included and used ketoconazole (22), ${ }^{82-101}$ itraconazole (9), ${ }^{102-110}$ or fluconazole (7). ${ }^{11-117}$ (Tables S12 to S14). Aside from standard regimens given in the included RCTs, the trials also included longer duration (2 months) and higher daily dose regimens (200 mg BID itraconazole; $300 \mathrm{mg}$ BID fluconazole). Compliance was measured in only four studies, through personally administered or supervised drug intake (3), or patient diary/blister reconciliation card.

Details of clinical adverse effects were poorly reported. Only a few studies stated definition (1), severity (3), course/ resolution (13), withdrawals due to adverse effects (18), and drug attribution (7). Laboratory monitoring was performed in only 32 studies.
Eighteen were parallel-group and individual-assigned $\mathrm{CCTs}$ while 38 were before-and-after trials. Trials were published between 1980 and 2007, with majority (31) published in the 1980s. Reports were mostly in English (32). Trials were generally small-sized (34) with less than 50 participants. Pharmaceutical funding or affiliation was present in a third of the studies (17), and majority did not state funding or conflict of interest (38).

\section{Risk of bias in included studies}

Overall, trials were poorly reported with generally unclear or high risk of bias (Figures S3 and S4). All trials were high risk of selection bias due to lack of randomization (15) or quasi-randomization (3). Only two CCTs were blinded. All 38 SATs did not have comparator groups (38).

\section{Effects of Interventions (NRS): Adverse effect outcomes}

Among nine CCTs that had events, only six $(n=324)$ contributed data but could not be pooled. There was no significant difference in clinical adverse effects in individual studies that compared triazole vs ketoconazole ${ }^{66}$ fluconazole vs itraconazole, ${ }^{68}$ divided daily dose vs single daily dose, ${ }^{74} 10$ day vs 20 -day ketoconazole, ${ }^{78} 5$ - vs 7 -day itraconazole, ${ }^{81}$ and 5 -vs 10- and 15-day itraconazole ${ }^{80}$ (Table S11).

There were 30 SATs $(n=1461)$ that contributed data for adverse effect outcomes. Pooled absolute risk for clinical adverse effects was highest for itraconazole (4.52\%, $95 \%$ CI 2.93, 6.43; 6 trials, $\mathrm{n}=664 ; \mathrm{I}^{2}=9.4 \%$ ) while the highest absolute risk for laboratory abnormalities was for ketoconazole $(2.55 \%, 95 \%$ CI 1.10, 4.58; 9 trials, $n=304$; $\mathrm{I}^{2}=0 \%$ ) (Table S15). There was no significant heterogeneity for all pooled data.

Based on all trials, the most common organ systems involved were gastrointestinal (1.75 to $2.46 \%$ ), neurologic (0.99 to $1.10 \%)$, and hepatobiliary (0.85 to $0.93 \%)$. All adverse effects were uncommon (below 1\%). The most commonly noted adverse effects were headache (0.68 to $0.97 \%$ ) and abnormal hepatic tests (0.81 to $0.85 \%)$ (Table S16). Most adverse effects were minor, except for nine 
which required treatment discontinuation and one which required hospitalization. Seven adverse effects (insomnia, headache, malaise, abdominal pain, dyspepsia, urticaria, and dermatitis) were reported in six participants after intake of ketoconazole in five SATs while two adverse effects (vomiting, dizziness) were reported in two participants after intake of itraconazole in one RCT. One serious adverse effect was reported in a participant with a recent gastric ulcer bleed who was 'inadvertently admitted to the study.' Participant was hospitalized and given medical treatment for two weeks due to the recurrent bleed.

\section{DISCUSSION}

\section{Summary of main results}

The key findings of this review are that oral azoles may be more effective than placebo and probably as effective as topical agents, and that oral triazoles may be equally effective as ketoconazole.

The question on the safety of oral azoles as a class, for a superficial skin infection such as PV, remains. In general, the trials in this review had inadequate monitoring, lack of blinding, and poor and selective reporting which may have underestimated the true risk for harm. In addition, the clinical trials were primarily powered for efficacy outcomes, and inadequate to detect differences in risk of harm for uncommon and rare adverse events. The regimens used were short duration and lower dose, and the highly selected clinical trial patient population may have been low-risk. We did not find any unpublished controlled trials, analytic observational studies, and pharmacoepidemiologic studies, and thus we cannot rule out serious hepatotoxicity or cardiotoxicity due to oral azoles.

\section{Overall completeness and applicability of evidence}

Although we included a sizable number of RCTs (38), only a few could be pooled for efficacy outcomes for key comparisons (oral azole vs placebo, $3 / 6$; oral azole vs topical agent, 4/9; triazole vs ketoconazole, 4/4). A larger number of included individual RCTs compared a variety of dosing regimens (18). Thus, only a few studies could be pooled, with some having significant heterogeneity. In addition, most trials were small-sized, which further contributed to imprecise effect estimates. There was also high risk of detection and performance bias due to lack of blinding. Therefore, quality of evidence was low to moderate for efficacy, and very low for harms (Summary of Findings tables in Tables S17 to S19).

Majority of trials were published in the 1980s and 1990s, with no recent publications, the latest being in 2010. This may have been due to the early reports of hepatotoxicity, especially for ketoconazole in the mid-1980s, which led to its ban in 2013. Poor reporting of baseline extent and recurrence also did not allow us to explore the impact of these patient characteristics in the treatment response to oral azoles, especially since the indication for it use include extensive and recurrent PV.
Although most RCTs (30) reported on mycologic cure, not all reported clinical cure (17) and recurrence (12). Some general clinics, especially in remote communities, with limited access to standard microscopic examination, would rely more on clinical cure. Criteria for clinical cure were also not standardized, with discoloration being considered as clinical failure in some studies. Lack of patient-reported outcomes, such as quality of life, also limits the applicability of evidence, especially for dark-skinned individuals who may have cosmetically disfiguring post-PV discoloration. Although we had an additional 56 non-randomized trials (18 CCTs and 38 SATs) for harm assessment, we did not get any unpublished trials or analytic observational studies. Thus, risk of harm may have been underestimated. In addition, the trials had inadequate monitoring, as most trials used passive detection, and not all trials (only 25/38 RCTs and 32/56 nonrandomized trials) did laboratory monitoring.

\section{Quality of evidence}

Nevertheless, the recommendation in current practice guidelines for oral azoles as a second-line treatment to topical agents is supported by the equivalent efficacy of the two treatments based on moderate quality of evidence (Table S18: Summary of Findings Table 2). Both can reach adequate therapeutic skin levels despite different routes. The nonsignificant trend in this review towards lower recurrence and shorter duration to cure for oral azoles need to be confirmed in future RCTs. Compliance was not widely monitored, and thus, it is difficult to determine its impact if participants had poor compliance with topical agents. It is still prudent to reserve oral azoles for patients who have failed topical treatment or cannot tolerate cutaneous adverse effects.

Triazoles are probably as effective as ketoconazole, based on moderate quality of evidence (Table S19: Summary of Findings Table 3). We conditionally support the recommendation of current practice guidelines on the use of triazoles instead of ketoconazole as second-line treatment for $\mathrm{PV}$. Together with the regulatory ban on oral ketoconazole for all indications, including $\mathrm{PV}$, we also note the finding of a serious and unexpected adverse effect, recurrent gastric ulcer bleed after intake of ketoconazole in a single-arm trial, though of unclear drug causality. In addition, five participants in five single-arm trials who discontinued the study due to adverse effects took ketoconazole. We also noted in this review that although triazoles may have a slightly higher risk of clinical adverse effects, these were all minor and dose-dependent, and may be reduced through divided or lower daily doses.

There is uncertainty on the efficacy of fluconazole compared to itraconazole, based on very low quality of evidence. Nevertheless, we conditionally recommend fluconazole over itraconazole since the former is more bioavailable, and has more convenient pulsed dosing. In addition, it has less drug interactions and may be less likely to induce antifungal resistance than itraconazole, which is a broad-spectrum drug. 


\section{Agreements and disagreements with other studies or reviews}

Compared to a previous systematic review, ${ }^{2}$ we included 15 more RCTs (38 vs 23), including 13 published before the 2008 search date, and 5 foreign-language RCTs compared to English-only in the previous review. This review agrees with their conclusion that oral azoles are more effective compared with placebo, but due to few pooled studies and participants and suspected publication bias, we assessed the evidence to be low quality. While the previous review concluded that RCTs are needed to compare relative efficacy of topical and systemic agents for PV, this review showed equivalent efficacy between oral azoles and topical agents, and triazole and ketoconazole, based on moderate quality of evidence. The previous review only determined the types of reported adverse effects, while this review also determined the relative risk of adverse effects. However, since we did not find any unpublished trials and observational studies, the risk of harm may have been underestimated.

\section{CONCLUSIONS}

Oral azoles may be more effective than placebo, and are probably as effective as topical agents. Triazoles are probably as effective as ketoconazole. Adverse effects after intake of oral azoles were mostly minor, transient, and did not require treatment discontinuation.

\section{RECOMMENDATIONS}

Oral azoles are conditionally recommended as a secondline option for patients who have failed treatment with topical agents. Triazoles are conditionally recommended over ketoconazole. Fluconazole is conditionally recommended over itraconazole, especially for patients with co-morbidities and concurrent medications. Choice of treatment should also be guided by cost and convenience. To confirm efficacy and safety, adequately-sized high quality RCTs and analytic observational studies and pharmacoepidemiologic studies must be conducted. Network meta-analysis of existing $\mathrm{RCT}$ s may be done to determine optimal dosing regimen.

\section{Acknowledgments}

We thank the other masters thesis panel members Drs. Marissa Alejandria and Francisca Roa. We also thank our co-reviewers Drs. Joel TM Bamford, Martha Morales, Ma. Assumpta Cecilia R. Serrano, Chandra Meghrajani, Katrina Aligam, Karen Marie G. Flores, Sharlene Pelino, and Annie Alvarez. We also thank Drs. Joel TM Bamford, Michael Bigby, Nazrul Islam Siddiqui, Mara Theresa Evangelista, Jose Frias, and Camilla S. Ribeiro; and Mr. Patrick Joseph Aldea, for providing full reports of the studies included in the review.

\section{Statement of authorship}

All authors have approved the final version submitted.

\section{Authors disclosure}

All the authors declared no conflicts of interest.

\section{Funding Source}

This paper was funded by the University of the Philippines Manila, Anatomy Cadaver Trust Fund and Graduate Thesis Fund.

\section{Note}

Supplementary tables (Table S1 to S17) and figures (Figure S1 to S4) mentioned in the text may be requested from the corresponding author.

\section{REFERENCES}

1. Kaymak E. Anxiety and depression in patients with pityriasis rosea compared to patients with tinea versicolor. Dermatol Nurs. 2008;20(5):367-77.

2. $\mathrm{Hu}$ S, Bigby M. Pityriasis versicolor. Arch Dermatol. 2010;146(10):1132-40.

3. Elewski BE, Hughey LC, Sobera JO, Hay R.; in Bolognia, JL, Jorizzo J.L., Schaffer JV (eds). Chapter 77: Fungal diseases. In: Dermatology 3rd Ed. ; 2012:1251-5.

4. Gupta AK, Lane D, Paquet M. Systematic review of systemic treatments for tinea versicolor and evidence-based dosing regimen recommendations. J Cutan Med Surg. 2014;18(2):79-90. doi:10.2310/7750.2013.13062.

5. European Medicines Agency. Ketoconazole Article-31 referral - European Medicines Agency recommends suspension of marketing authorisations for oral ketoconazole. 2013;44(July):4-6. doi:WC500146616.

6. U.S. Food and Drug Administration. FDA Drug Safety Communication: FDA limits usage of Nizoral (ketoconazole) oral tablets due to potentially fatal liver injury and risk of drug interactions and adrenal gland problems. [Online] 2013 [cited 2013]. Available from www.fda.gov/downloads/Drugs/DrugSafety/UCM362444.pdf.

7. Republic of the Philippines Food and Drug Administration. FDA Circular No. 2013-028: Suspension of Manufacture, Importation, Distribution and or Marketing of Ketoconazole Oral Products. [Online] 2013 [cited 2013]. Available from www.fda.gov.ph/ issuances/127970\%0Afda-circular-no2013\%0A.

8. Review Manager (RevMan). [Computer Program]. Version 5.3. Copenhagen. The Nordic Cochrane Center. The Cochrane Collaboration. 2014.

9. StatsDirect Ltd: England. StatsDirect. [Online] 2013 [cited 2013]. Available from http://www.statsdirect.com.

10. Schünemann H, Brożek J, Guyatt G. Oxman A (editors). GRADE. GRADE handbook for grading quality of evidence and strength of recommendations. The GRADE Working Group. [Online] 2013 [cited 2013]. Available from www. guidelinedevelopment.org/handbook.

11. Borelli D, Borelli K, Barros J. Pitiriasis versicolor. Recaída después de dosis única de quetoconazol [Pityriasis versicolor relapse after single dose ketoconazole]. Derm Venez. 1995;33(1):35-7.

12. Difonzo EM. Italian multicentre study with oral itraconazole in recurrent pityriasis versicolor . Preliminary report. J Eur Acad Dermatol Venereol. 1992;1:S19-20.

13. Faergemann J. The efficacy of oral treatment with pramiconazole in pityriasis versicolor : a phase II a trial. Br J Dermatol. 2007;156:1385-9. doi:10.1111/j.1365-2133.2007.07888.x.

14. Faergemann J, Todd G, Pather S, et al. A double-blind, randomized, placebo-controlled, dose-finding study of oral pramiconazole in the treatment of pityriasis versicolor.J Am Acad Dermatol.2009;61(6):9716. doi:10.1016/j.jaad.2008.08.033.

15. Marcano C, Rodríguez H, Borelli D. Tratamiento de micosis superficiales con itraconazol [Treatment of superficial mycosis with itraconazole]. Derm Venez. 1986:124-7. 
16. Borelli D. Treatment of pityriasis versicolor with ketoconazole. Rev Infect Dis. 1980;2(4):592-5.

17. Sugai, T, Shoji A. Oral itraconazole in patients with superficial mycoses: An open trial of 23 cases (Japanese). Skin Res. 1991;33(2):212-9.

18. Wang Z, Li X, Chen Z. 63 cases curative effect observation of itraconazole in treating the ringworm of the body and groin and tinea versicolor (Chinese). Chinese J Dermatovenereology. 2000;14(5):356.

19. Wang Y, Liu J, Liu L, Teng W. A comparative clnical study of the consolidation treatment of itraconazole in pityriasis versicolor. J Clin Dermatol. 2006;35(6):376-7.

20. Zhu Y, Zhang S, Wei G. The clinic analysis of 157 case tinea versicolor and the curative report of ketoconazole for it (Chinese). Chinese J Dermatovenereology. 1993;7(2):96.

21. Aalami H. Systemic ketoconazole in the treatment of recurring tinea versicolor (Abstract). Ann Dermatol Venereol. 2002;129:1462.

22. Mohanty J, Sethi J, Sharma M. Efficacy of itraconazole in the treatment of tinea versicolor. Indian J Dermatol Venereol Leprol. 2001;67(5):240-1

23. Muhammad N, Kamal M, Islam N, Shafiquzzaman M. A study to evaluate the efficacy and safety of oral fluconazole in the treatment of tinea versicolor. Mymensingh Med J. 2009;18(1):31-5.

24. Padilha A, Gontijo B, Bartelli C, Al E. Tratamento das dermatimicoses com ketoconazole por via oral: Estudo multicentrico (Spanish) [Treatment of dermatomycoses with oral ketoconazole: Multicentric study]. An Bras Dermatol. 1984;59(4):202-8.

25. Grigoriu A, Grigoriu D. Superficial mycoses: Ketoconazole treatment. Mykosen. 1982;25(5):258-62.

26. Conti-Diaz I, Civila E, Asconegui F. Treatment of superficial and deep-seated mycoses with oral ketoconazole. Int J Dermatol. 1984;23:207-11.

27. Zucchi A, De Panfiliis G, Allegra F. Il fluconazolo nel trattamento delle epidermomicosi [Fluconazole in the treatment of dermatomycoses]. G Ital Dermatol Venereol. 1990;125(1-2):1-3.

28. Balachandran C, Thajuddin, Ravikumar B. Comparative evaluation of single dose regimen with two dose regimen of fluconazole in the treatment of tinea versicolor : A double blind placebo controlled study. Indian J Dermatol Venereol Leprol. 1999;65:20-2.

29. Urcuyo FG, Zaias $\mathrm{N}$. The successful treatment of pityriasis versicolor by systemic ketoconazole. J Am Acad Dermatol. 1982;6:24-5.

30. Hickman JG. A double-blind, randomized, placebo-controlled evaluation of short-term treatment with oral itraconazole in patients with tinea versicolor. J Am Acad Dermatol. 1996;34(5.1):785-7.

31. Ravikumar B, Balachandran C, Sabitha L. Single dose itraconazole therapy in tinea versicolor; a double blind, randomised placebo controlled study. Indian J Dermatol Venereol Leprol. 1999;65:151-2.

32. Savin R. Systemic ketoconazole in tinea versicolor: A doubleblind evaluation and 1-year follow-up. J Am Acad Dermatol. 1984;10(5.1):824-30.

33. Zaias N. Pityriasis versicolor with ketoconazole.J Am Acad Dermatol. 1989;20(4):703-4.

34. Atefi N. Comparative study of fluconazole pulse therapy with selenium sulfide shampoo in the treatment of pityriasis versicolor (Abstract, 20th World Congress of Dermatology Paris 1st to 5th July 2002). Ann Dermatol Venereol. 2002;129:1465.

35. Dehghan M, Akbari N, Alborzi N, Sadani S. Single-dose oral fluconazole versus topical clotrimazole in patients with pityriasis versicolor : A double-blind randomized controlled trial. J Dermatol. 2010;37:699-702. doi:10.1111/j.1346-8138.2010.00908.x.

36. del Palacio A, Delgado V, Ramos F, Belaustegui A. Randomized comparative clinical trial of itraconazole and selenium sulfide shampoo for the treatment of pityriasis versicolor. Rev Infect Dis. 1987;9(1):S121-7.

37. Kim J, Lee J, Jeong E. Clinical study and therapeutic experience in tinea versicolor. Korean J Dermatol. 1986;24(1):55-60.

38. Kim J, Jun K, Ro Y, Kim J. Clinical study and therapeutic experience in tinea versicolor (2). J Korean Med Assoc. 1991;34(8):875-900.

39. Kim J, Kim J. Clinical study and therapeutic experience in tinea versicolor. Korean J Dermatol. 1995;33(2):280-6.
40. Nagpal V, Jain V, Aggarwal K. Comparative study of oral and topical ketoconazole therapy in pityriasis versicolor. Indian J Dermatol Venereol Leprol. 1993;69(4):287-8.

41. Patel K, Vora N, Dave J, Mukhopadhyay A. Comparative study of oral versus topical ketoconazole therapy in pityriasis versicolar. Indian J Dermatol Venereol Leprol. 1993;59:279-80.

42. Silva $\mathrm{H}$, Arguedas J, Behalf ON, et al. A comparison of fluconazole with ketoconazole, itraconazole, and clotrimazole in the treatment of patients with pityriasis versicolor. Curr Ther Res. 1998;59(4):203-14.

43. Bhogal C, Singal A, Baruah M. Comparative efficacy of ketoconazole and fluconazole in the treatment of pityriasis versicolor: A one year follow-up study. J Dermatol. 2001;28:535-9.

44. Farshchian M, Yaghoobi R, Samadi K. Fluconazole versus ketoconazole in the treatment of tinea versicolor. J Dermatol Treat. 2002;13(2):73-6.

45. Yazdanpanah MJ, Azizi H, Suizi B. Comparison between fluconazole and ketoconazole effectivity in the treatment of pityriasis versicolor. Mycoses. 2007;50(4):311-3. doi:10.1111/j.1439-0507.2007.01361.x.

46. Shemer A, Nathansohn N, Kaplan B, Trau H. Itraconazole versus ketoconazole in the treatment of tinea versicolor. J Dermatol Treat. 1999;10:19-23

47. Montero-Gei F, Robles M, Suchil P. Fluconazole vs itraconazole in the treatment of tinea versicolor. Int J Dermatol. 1999;38(8):601-3.

48. Fernandez-Nava HD, Laya-Cuadra B, Tianco EA V. Comparison of single dose $400 \mathrm{mg}$ versus 10 -day $200 \mathrm{mg}$ daily dose ketoconazole in the treatment of tinea versicolor. Int J Dermatol. 1997;36:64-7.

49. Köse O, Tastan HB, Gür AR, Kurumlu Z. Comparison of a single $400 \mathrm{mg}$ dose versus a 7-day $200 \mathrm{mg}$ daily dose of itraconazole in the treatment of tinea versicolor. J Dermatol Treat. 2002;13:779.

50. Wahab M, Ali M, Rahman M, et al. Single dose (400mg) versus 7 Day (200mg) daily dose itraconazole in the treatment of tinea versicolor: A randomized clinical trial. Mymensingh Med J. 2010;19(1):72-6.

51. Dogan C, Saracoglu Z, Urer S, Sabuncu I. Pitiryazis versikolorda oral flukonazolun uc farkli dozda etkisinin arastirilmasi [Investigation of the efficacy of oral fluconazole with three different dose schedules in pityriasis versicolor.] Turkiye Klin J Dermatol. 1999;9:137-42.

52. Estrada R. Itraconazole in pityriasis versicolor. Rev Infect Dis. 1987;9(1):s128-30.

53. Morales-Doria M. Pityriasis versicolor: efficacy of two five-day regimens of itraconazole. Rev Infect Dis. 1987;9(Suppl 1):S131-3.

54. Amer MA. Fluconazole in the treatment of tinea versicoior. Egyptian Fluconazole Study Group. Int J Dermatol. 1997;36:938-46.

55. del Palacio-Hernanz A, Frias-Iniesta J, Gonzalez-Valle O, et al. Itraconazole therapy in pityriasis versicolor. Br J Dermatol. 1986;115:217-25.

56. Anwer J, Iqba P, Aghai R, et al. The treatment of dermatophytoses and pityriasis versicolor with one week orally administered itraconazole. J Pak Med Assoc. 2001;11:60-3.

57. Barile F, Filotico R, Grandolfo M. Pityriasis versicolor trattata con itraconazolo (R51211), secondo due schemi posologici per os [Pityriasis versicolor treated with itraconazole (R51211), according to two oral dosage schemes]. Chron Derm. 1990;21(4):519-24.

58. Fioroni A, Cilli P, Altomare G, Finzi A. Itraconazole: A new oral antimycotic for the treatment of pityriasis versicolor. Comparative clinical study of two treatment regimens. Micol Dermatol. 1992;6:43-6.

59. Hay R, Midgeley G. Short course ketoconazole therapy in pityriasis versicolor. Clin Exper Dermatol. 1984;9:571-3.

60. Kokturk A, Kaya T, Ikizoglu G, et al. Efficacy of three short-term regimens of itraconazole in the treatment of pityriasis versicolor. J Dermatol Treat. 2002;13:185-7.

61. Galimberti R, Villalba I, Galarza S, et al. Ketoconazol suspension oral adultos en el tratamiento de la pitiriasis versicolor [Ketoconazole oral suspension in the treatment of adults with pityriasis versicolor]. Rev Infect Dis. 1987;9(1):317-31.

62. Faergemann J. Treatment of pityriasis versicolor with itraconazole. Mykosen. 1987;30(1):44-7.

63. Partap R, Kaur I, Chakrabarti A, Kumar B. Single-dose fluconazole versus itraconazole in pityriasis versicolor. Dermatology. 2004;208:55-9. doi:10.1159/000075047. 
64. Faergemann J. Treatment of pityriasis versicolor with itraconazole: a double-blind placebo controlled study. Mycoses. 1988;31(7):377-9.

65. Roseeuw D, Willemsen M, Kint R, et al. Itraconazole in the treatment of superficial mycoses - a double-blind study vs placebo. Clin Exper Dermatol. 1990;15:101-5.

66. Handjani F, Nasseri M. Comparison of a single oral dose of fluconazole with ketoconazole in the treatment of tinea versicolor. J Dermatol. 2003;6(4):2-6

67. Çesme M, Özarmagan G. Pitiriyazis versikolorda sistemik flukonazol ve itrakonazolün etkinliği: Karşılaştırmalı çalı̧̧ma [Efficacy of fluconazole and itraconazole in the treatment of pityriasis versicolor]. Turkderm. 2003;37(2):114-6.

68. Kose O. Fluconazole versus itraconazole in the treatment of tinea versicolor. Int J Dermatol. 1995;34(7):498-9.

69. Khan MM, Noor SM. Comparison of two dosage regime of ketoconazole in the tretment of pityriasis versicolor. J Postgrad Med Inst. 2006;20(3):288-91.

70. Sadeque J, Shahidullah M, Shah O, Kamal M. Systemic ketoconazole in the treatment of tinea versicolor. Int J Dermatol. 1995;34(7):504-5.

71. Sampaio S, Freitas T, Sabogal M. Tratamento da pitiriase versicolor pelo ketoconazole [Treatment of pityriasis versicolor by ketoconazole]. An Bras Dermatol. 1983;58(6):245-8.

72. Zheng H. Comparative study of four little dose ketoconazole for tinea versicolor (Chinese). Chinese J Ski Venereol. 1994;8(3):158-9.

73. Biggio P, Aste N, Pau M. Primi risultati dell'impiego dell'Itraconazolo (R 51-211) nel trattamento della pitiriasis versicolor [First results of the use of itraconazole ( $\mathrm{R}$ 51-211) in the treatment of pityriasis versicolor]. Derm Clin. 1986;(3):251-5.

74. Panconesi E, Difonzo E. Treatment of dermatophytoses and pityriasis versicolor with itraconazole. Rev Infect Dis. 1987;9(1):S109-13.

75. Simoni S, Cilli P. l'itraconazolo nel trattamento della pytiriasis versicolor Risultati ottenuti in trenta pazienti [Itraconazole in the treatment of Pytiriasis versicolor. Results in thirty patients]. G Ital Dermatol Venereol. 1991;126(11):41-3.

76. Elorfi A. Itraconazole for pityriasis versicolor (Abstract). Ann Dermatologie Venereol. 2002:1483.

77. Palacio AH, Frias JI, Gonzales OV, et al. Tratamiento corto con ketoconazol sistemico en pitiriasis versicolor [Short treatment with systemic ketoconazole in pityriasis versicolor]. Farm Clin. 1985;2(6):428-33.

78. Sampaio S, Zeminian P, Salebian A. Ketoconazole na pitiriase versicolor: Estudo comparativo entre dois periodos de tratamento, 10 e 20 dias [Ketoconazole in pityriasis versicolor: A comparative study between two treatment periods, 10 and 20 days]. An Bras Dermatol. 1985;60(1):41-4.

79. Selim M, Kubec K. Pityriasis versicolor - Epidemiological and therapeutical study. Mycoses. 1989;32(2):100-3.

80. Delescluse J, Cauwenbergh G, Degeef H. Itraconazole, a new orally active antifungal, in the treatment of pityriasis versicolor. $\mathrm{Br} J \mathrm{Dermatol}$. 1986;114:701-3.

81. Cuce LC, Belda Jr W, Ribeiro EB de O. Itraconazole no tratamento da pitiriase versicolor: Comparacao entre 5 e 7 dias de tratamento [Itraconazole in the treatment of pityriasis versicolor: Comparing between 5 and 7 days of treatment]. Rev Inst Med Trop Sao Paulo. 1990;32(3):181-4.

82. Biggio P, Aste N, Mulas P, Orru A. Ketoconazole: Therapeutic results obtained in the district of Cagliari. Drugs Exp Clin Res. 1986;12(5):415-8

83. Alteras I, Sandbank M, Segal R. 60 cases of pityriasis versicolor: Two years of follow-up of oral ketoconazole therapy. Dermatologica. 1987;144:142-4.

84. Arenas R, Balcazar G, de la Cruz F, Garibay JM. Pitiriasis versicolor, tratamiento corto con ketoconazol en 56 pacientes [Pityriasis versicolor, short treatment with ketoconazole in 56 patients.]. Invest Med Int. 1989;16(1):29-31.

85. Chaparro G V., Gonzalez G. Ketoconazol en pitiriasis versicolor [Ketoconazole in pityriasis versicolor]. Trib Medica. 1985;71(9):25-6.

86. De la Cruz J. Evaluacion terapeutica del ketoconazole en la pitiriasis versicolor [Therapeutic evaluation of ketoconazole in pityriasis versicolor]. Compend Investig Clin Latinamericanas. 1982:47-8.

87. Faergemann J, Djarv L. Tinea versicolor: treatment and prophylaxis with ketoconazole. Cutis. 1982;30(4):542-5, 550.

88. Filguiera AL, de Assis TL, Azulay RD. Cetoconazol no tratamento da pitiríase versicolor por 10 dias [Ketoconazole in the treatment of pityriasis versicolor during 10 days]. An Bras Dermatol. 1987;62(2):119-23.

89. Galimberti R. Tratamiento oral con ketoconazole de micosis superficiales [Oral treatment of superficial mycoses with ketoconazole]. Rev Arg Dermatol. 1983;64:442-7.

90. Galimberti R, Chouela E, Casala AM, Flores V. Oral ketoconazole suspension in the treatment of the pityriasis versicolor. Arch Argent Dermatol. 1986;36(5):317-31.

91. Giam YC, Rajan VS. Oral ketoconazole - A new treatment for tinea versicolor. Singapore Med J. 1984;25(3):157-160.

92. Giam YC, Tham SN. Ketoconazole in Tinea versicolor: Is ten-day therapy adequate? Singapore Med J. 1987;28(1):13-7.

93. Jolliffe DS, Ngai YL. Systemic treatment of tinea versicolor with ketoconazole in forty-four patients. Clin Exp Dermatol. 1981;6:625-8.

94. Kaur I, Kumar B, Sharma VK. Oral ketoconazole in tinea versicolor. Indian J Dermatol Venereol Leprol. 1991;57(3):157-8.

95. Mapurunga ACP, Gonçalves G, Macial H, Coaraci MM. Cetoconazol no tratamento da pitiríase versicolor em dose única [Treatment of pityriasis versicolor with ketoconazole in single dose]. Farmacol Clin. 1992;104(3):97-9.

96. Obasi OE, Ozoh G. Ketoconazole treatment of dermatomycoses in Kaduna, Nigeria. Curr Ther Res. 1988;43(5):931-41.

97. Padilha-Gonçalves A, Ferreira AJ, Monteiro CM. Ketoconazole in the treatment of pityriasis versicolor: 10-day schedule [Cetoconazol no tratamento da pitiríase versicolor: esquema de 10 dias,]. Farmacol Clin. 1987;94(5):321-3.

98. Rausch LJ, Jacobs PH. Tinea versicolor: treatment and prophylaxis with monthly administration of ketoconazole. Cutis. 1984;34:470-1.

99. Schewach-Millet M, Kahana M, Levy A, Yaron-Schiffer O, Sommer B, Shalish L. Ketoconazole - an effective treatment for disseminated pityriasis versicolor. Isr J Med Sci. 1984;20:417-9.

100. Torok I, Simon G, Pap M. An evaluation of two years of clinical experience with ketoconazole. Mykosen. 1982;25(3):136-42.

101. Welsh O, Rodriguez M. Treatment of Dermatomycoses with Ketoconazole. Rev Infect Dis. 2014;2(4):582-85.

102. Chang SH, Suh DH, Kim SH, Youn JI. A clinical study of oral itracoazole therapy in tinea versicolor. J Korean Med Assoc. 1991;34(2):197-202.

103. Faergemann J, Gupta AK, Al Mofadi A, et al. Efficacy of itraconazole in the prophylactic treatment of pityriasis (tinea) versicolor. Arch Dermatol. 2002;138(1):69-73.

104. Georgiou S, Monastirli A, Pasmatzi E, et al. Oral itraconazole therapy for pityriasis versicolor. J Eur Acad Dermatology Venereol. 1997;8(3):203-7.

105. Gontijo B. Itraconazol no tratamento da pitiriase versicolor: esquema de cinco dias [Itraconazole in the treatment of pityriasis versicolor: scheme five days]. Clin Pharmacol. 1993;68(2):121-4.

106. Karincaoglu Y, Dogan G, Hazneci E, Ozcan H. Tek doz itrakonazol ile tinea versikolor tedavisi (Treatment of pityriasis versicolor with a single dose of itraconazole]. Turkderm. 2001;35:40-2.

107. Robertson LI. Itraconazole in the treatment of widespread tinea versicolor. Clin Exp Dermatol. 1987;12:178-80.

108. Saul A, Bonifaz A, Arias I. Itraconazole in the treatment of superficial mycoses: an open trial of 40 cases. Rev Infect Dis. 1987;9(1):S100-3.

109. Zaitz C, Sampaio S. Avaliacao da eficacia e tolerabilidade do itraconazol no tratamento da pitiriase versicolor [Evaluation of the efficacy and tolerability of itraconazole in the treatment of pityriasis versicolor]. An Bras Dermatol. 1995;70(3):195-8.

110. Zeminian PS, Bender AT, Ribeiro E, et al. Tratamento sistêmico da pitiríase versicolor pelo itraconazol [Systemic treatment of pityriasis versicolor with itraconazole ]. An Bras Dermatol. 1987;62(3):187-8.

111. Balaban D, Ersoy L. Yuzeyel mikozlarin oral flukonazol'le tedavisi [Treatment of topical mycoses with oral fluconazole]. Turkderm. 1995;29:22-4. 
112. Faergemann J. Treatment of pityriasis versicolor with a single dose of fluconazole. Acta Derm Venereol. 1992;72:74-5.

113. Karakas M,Durdu M, Memisoglu H. Oral fluconazole in the treatment of tinea versicolor. J Dermatol. 2005;32:19-21.

114. Khan MM, Noor SM, Nawaz K. Single dose fluconazole in the treatment of pityriasis versicolor. J Pak Med Assoc. 2007;17:28-31.

115. Rao S, Rajashekhar N. Oral fluconazole in tinea versicolor. Indian J Dermatol Venereol Leprol. 1997;63(3):166-7.
116. Schiaramazzi B, Cavarischia R, Assalve D, et al. Valutazione dell'efficia e della tollerabilita del trattamento con fluconazole nelle infezioni fungine cutanee (Evaluation of the effectiveness and tolerance of the treatment with fluconazole in mycotic and candida infections of the skin). Gaz Med Ital Arch Sci Med. 2003;162:155-9.

117. Shahid J, Ihsan Z, Khan S. Oral fluconazole in the treatment of pityriasis versicolor. J Dermatol Treat. 2000;11:101-3.

\section{The Acta Medica Philippina is now accepting limited} advertising for its front and back cover (colored), as well as for available spaces in some of its pages, as appropriate. For inquiries and submission of proposals, please e-mail us at actamedicaphilippina@yahoo.com 